\title{
John Henry Newman, Edith Stein y la soberanía de la autoconciencia.
}

John Henry Newman, Edith Stein and the sovereignty of Self-Consciousness.

Jacinto Choza ${ }^{1}$

Universidad de Sevilla, España.

Ananí Gutiérrrez Aguilar ${ }^{2}$

Universidad Nacional de San Agustín, Arequipa, Perú.

Recibido 14 septiembre 2020 . Aceptado 20 noviembre 2020

\section{Resumen}

En este artículo se expone la recepción del pensamiento de John Henry Newman y de Edith Stein en los cuadros teológicos y eclesiásticos oficiales de la iglesia católica. Recoge una parte de la historia de la guerra entre política y religión de la era contemporánea, en una parte de las iglesias cristianas de occidente.

Esa guerra es la resistencia del Antiguo Régimen, frente al nuevo orden que a finales de la modernidad inauguran las proclamaciones de la dignidad del hombre, de los derechos humanos y de la soberanía de la autoconciencia.

La recepción de Newman y Stein significa el reconocimiento de los derechos humanos y la dignidad humana en los ámbitos cristianos, y especialmente en la iglesia católica.

Palabras clave: Persona, conciencia, autoconciencia, personalismo, Iglesia católica

\section{Abstract}

This article presents the reception of the thought of John Henry Newman and Edith Stein in the official theological and ecclesiastical circles of the Catholic Church. It collects a part of the history of the war between politics and religion of the contemporary era, in a part of the Christian churches of the West.

This war is the resistance of the old Regime, against the new order that at the end of modernity inaugurates the proclamations of the dignity of man, human rights and the sovereignty of self-consciousness.

The reception of Newman and Stein signifies the recognition of human rights and human dignity in the aforementioned religious fields.

Keywords: Person, conscience, self-conscience, personalism, Catholic Church 


\section{La soberanía de la autoconciencia en la modernidad. Contextualización histórica}

El tema de la libertad del sujeto, de la libertad como fundamento del pensamiento teórico, y de la soberanía de la autoconciencia como fundamento de la dignidad humana, de la acción práctica, moral y política, es una de las claves, quizá la principal, del pensamiento y de la acción de la cultura moderna'.

Desde que Descartes establece el "yo pienso" como primer principio de la reflexión filosófica y de la acción práctica, la filosofía moderna pasa a tener como tema fundamental al ser humano, al que en la Antigüedad se designa como "hombre" (ánthropos), en la Edad Media como "persona", ahora "sujeto", para pasar a denominarse "existente" en el periodo contemporáneo más reciente.

La modernidad se centra en el estudio del hombre como sujeto, pero después de haber descubierto que ese sujeto, teniendo su fundamento en una naturaleza universal, lo tiene también, y más propiamente aún, en su libertad individual, es decir, en su singularidad personal.

A lo largo de la modernidad el hombre, manteniendo las claves y los criterios de su saber y de su actuar en una esencia universal, objetivamente definible y comunicable, empieza a descubrir que las tiene más propiamente en su singularidad personal incomunicable.

La universalidad de la naturaleza humana, y de la libertad humana, permite establecer el valor absoluto, o sea, la dignidad del ser humano singular, con carácter universal, para todos los individuos de la especie. Esta percepción de la libertad personal y de su carácter fundamental, se produce simultáneamente en las diversas esferas de la cultura, y la atención se centra preferentemente también en el estudio de ella.

En el plano teórico la formulación más paradigmática del valor infinito de la persona singular es la Fundamentación para la metafísica de las costumbres, de Kant, de 1796; en el plano teórico práctico de la economía, es

1 Cfr., Garay, J., El nacimiento de la libertad. Precedentes de la libertad moderna. Sevilla: Themata, (2) 2017. 
la Riqueza de las naciones de Adam Smith, publicada también en 1776, y en el plano práctico político, es la Declaración de Derechos de Virginia, de 1976 también.

La Declaración de Derechos de Virginia tiene como antecedente la Carta de Derechos Inglesa (Bill of Rights) de 1689, y sirve de inspiración a proclamaciones posteriores como la Declaración de los Derechos del Hombre y del Ciudadano de 1789, de Lafayette, en la Revolución francesa.

John Locke se considera uno de los principales inspiradores de esas tres declaraciones de derechos, que animan de varios modos las actuaciones conducentes a la toma de la bastilla de 1789 y la caída del Antiguo Régimen.

El descubrimiento del carácter fundamental del ser singular, más allá del carácter fundamental de la naturaleza universal, es un acontecimiento que impregna y determina la cultura del siglo XIX, y más aún la del XX.

En la política se manifiesta como liberalismo y nacionalismo político, en el arte como expresión de los sentimientos particulares y personales con el nombre de romanticismo y existencialismo.

En filosofía y en ciencia acontece también con características análogas. En filosofía como descubrimiento de un sujeto singular único, que es el de Kierkegaard, Dostoievski y Nietzsche, frente al sujeto trascendental kantiano. En ciencia, como nacimiento de las disciplinas que se ocupan del singular único, como la inmunología, la genética y la psicología, frente a las ciencias clásicas tradicionales, como la mecánica y la óptica, que se ocupan de leyes universales y necesarias de la naturaleza.

Esa transición de la naturaleza universal a la vida singular como fundamento, en la acción política y en la ciencia, tiene como una de sus expresiones más típicas la disputa sobre los métodos en las universidades alemanas en las últimas décadas del siglo XIX y primeras del XX, denominada "disputa sobre el método" o Methodenstreit, y también la disputa sobre las ciencias nomotéticas y las idiográficas².

La forma violenta de esa transición recibe, en política, el nombre de Caída del Antiguo Régimen según una expresión original de Tocqueville,

2 https://es.wikipedia.org/wiki/Methodenstreit; https://en.wikipedia.org/wiki/Nomothetic_and_idiographic 
que posteriormente se generaliza. Pasa entonces a significar sustitución de los regímenes políticos de las aristocracias y las monarquías absolutas por las repúblicas democráticas, o bien, desde el punto de vista sociológico, el paso de las sociedades estamentales a las sociedades burguesas, republicanas y democráticas.

Esa transición de la naturaleza universal a la libertad singular, resulta a veces violenta, debido a la resistencia ofrecida por el orden establecido ante la presión de propuestas innovadoras. La violencia es más perceptible y sangrienta en el campo de la política cuando acontecen procesos revolucionarios, y menos perceptible y menos sangrienta en el de la ciencia, la filosofía y la religión.

En la historia de occidente, la resistencia quizá más fuerte y prolongada a la caída del Antiguo Régimen, y a las proclamaciones de los derechos humanos de los movimientos liberales, se encuentra en las iglesias cristianas, orientales y occidentales, y, especialmente, en la iglesia católica.

En el orden práctico organizativo, la universalidad y objetividad de la naturaleza se expresa en los sistemas jurídicos administrativos del Antiguo Régimen, en su jerarquía patriarcal, tanto en los regímenes políticos y en los estados, como en la ortodoxia de las religiones y las iglesias.

El carácter prioritario de la persona sobre la naturaleza se expresa, en las proclamaciones de los derechos humanos, como exigencia de reconocimiento de derechos subjetivos: de la libertad religiosa, de pensamiento, de expresión, de enseñanza, etc.

Los estados del Antiguo Régimen son confesionales, y no aceptan las propuestas liberales de la desconfesionalización del Estado y de libertad religiosa. En occidente no la aceptan los estados de confesión católica, ni los de confesión protestante, y en oriente tampoco los de confesión ortodoxa. La proclamación de la dignidad de la persona y el nacimiento del liberalismo, adopta la forma de lucha de la sociedad civil contra el Estado confesional y contra la iglesia con la que está vinculado, sea protestante, católica u ortodoxa.

La libertad religiosa llega formalmente en los países protestantes con la Declaración de Derechos Humanos de 1948, y en los países orientales después de la descomposición de la Unión Soviética de 1992.

En los países protestantes, las iglesias nacionales aceptan los dere- 
chos humanos porque están integradas y obligadas a sumir las constituciones de sus países, que los aceptan a partir de 1948, y las iglesias ortodoxas, a partir de 1992, también.

Puede decirse que el enemigo principal de la proclamación de los derechos humanos y del liberalismo, y con una enemistad más intensa, es la iglesia católica, con sus sucesivas condenas, entre las que se cuentan algunos hitos destacados.

En 1832, la encíclica Mirari vos, de Gregorio XVI, aparece como primera condena oficial. Es un documento celebrado por la jerarquía católica de la iglesia francesa y española, que cuentan con estados confesionales católicos. Al mismo tiempo, la encíclica es silenciada por la jerarquía católica en Inglaterra, Países Bajos y Polonia, donde la iglesia católica sufre la opresión de sus respectivos estados confesionales, anglicanos, luteranos y ortodoxos, y tienen como aliados naturales a los liberales que piden la desconfesinalización del estado y la libertad religiosa ${ }^{4}$.

En 1864, el Syllabus o Índice de los principales errores de nuestra época de Pío IX, y en 1910 el Juramento antimodernista de Pio X, recogen y condenan como errores las tesis sobre los derechos humanos contenidos en las diversas declaraciones, desde la de Virginia de 1776 y la francesa de 1789, en adelante.

En 1950, la encíclica Humani generis de Pio XII, después de la Segunda Guerra Mundial, recoge y refuerza las condenas de sus antecesores en el pontificado 5 .

Desde comienzos del siglo XX, y en el siglo XXI, se amplía y se profundiza el proceso de fundamentación del humanismo, de la dignidad humana, de la acción práctica, moral y política, y en general, de los valores de la cultura occidental, en la libertad más bien que en la naturaleza.

La transición desde la naturaleza universal como fundamento a la singularidad de la persona como fundamento, se produce en el arte y la tec-

3 Este proceso está estudiado con detenimiento en Choza, J., Religión oficial y religión personal en la época histórica, Sevilla: Thémata, 2020.

4 Cfr., Redondo, Gonzalo, La Iglesia en el mundo contemporáneo, vol I, Pamplona: Servicio de Publicaciones de la Universidad de Navarra, 1981.

5 Este proceso está estudiado con detenimiento en Choza, J., Religión oficial y religión personal en la época histórica, Sevilla: Thémata, 2020. 
nología, en la política y la economía, en la ciencia y en la filosofía, y por supuesto en la religión.

Ese es el sentido que tienen en filosofía el existencialismo, la fenomenología, el pragmatismo, el psicoanálisis, la hermenéutica, la filosofía dialógica judía, el espiritualismo eslavo, y otros movimientos espiritualistas cristianos, de los cuales algunos se autodenominan explícitamente como personalismos.

En realidad, todas las corrientes filosóficas que buscan la fundamentación del ser, del saber y del actuar humano, más allá de la naturaleza universal, en la persona singular, se pueden considerar personalistas, aunque solamente algunas de ellas asumen tal denominación.

Desde comienzos del siglo XIX, y como puede advertirse en las mencionadas condenas del liberalismo, la iglesia católica interpreta esta evolución de la filosofía y de las ciencias en el sentido de un subjetivismo arbitrario, como un ataque al contenido de la religión, fundamentado en la naturaleza humana universal, y expresado y conservado en esa clave moderna6.

En 1963-65, el Concilio Vaticano II repasa y reformula la autoconciencia de la Iglesia en el mundo contemporáneo, y empieza a interpretar la evolución y las corrientes de pensamiento de los siglos XIX y XX, no en clave de un subjetivismo y arbitrario, sino en clave de una personalización del saber, el actuar y el ser del hombre, en clave de un reconocimiento de la libertad y dignidad de la persona humana como fundamento del saber y del actuar.

Ese trayecto lo realizan también, antes, después o simultáneamente, otras confesiones cristianas. El modo en que, en concreto, lo realiza la iglesia católica puede entenderse como una recepción en los cuadros oficiales de la teología católica, de la obra de John Henry Newman y de Edith Stein?.

Esa recepción es una parte de la historia de la guerra entre política y religión de era contemporánea, con sus particulares tratados de paz. Más particularmente, la parte de la guerra entre política y religión que se da en 
las iglesias cristianas de occidente, especialmente en la Iglesia católica.

No se puede decir que esa guerra haya terminado en el mundo cristiano, ni en ningún otro ámbito religioso y cultural. Esa guerra es la resistencia del orden de los dioses antiguos y de la naturaleza, frente al orden que inaugura el proceso de personalización, frente al reconocimiento de la soberanía de la persona en términos de reconocimiento de derechos subjetivos.

Esa guerra continúa en los diferentes países y áreas religiosas como guerra por la libertad de enseñanza, la libertad religiosa, y, más perceptiblemente, como guerra frente al último factor determinante de la naturaleza universal sobre la vida humana, a saber, el sexo. Lo que se reclama es el cese de la secular determinación en función de la naturaleza y el inicio de una determinación por parte de la libertad, de la persona. Los debates sobre la identidad sexual, el aborto, el matrimonio homosexual, la fecundación artificial, y en general, las reclamaciones del colectivo LGTBI, son actualmente el frente de ese combate entre política y religión, que en su forma contemporánea se inicia en 1789.

En el ámbito cultural luterano y anglicano, quizá puede decirse que el final de ese combate se ha alcanzado. En el cristianismo oriental y en el islam se encuentra en fases iniciales. En el ámbito católico, parece acercarse a medida que la recepción del pensamiento de Newman y Stein se hace más general.

\section{$2 \cdot$ La persona y la conciencia en la iglesia católica del siglo XXI}

En los últimos años han nacido al menos dos asociaciones para el estudio del pensamiento de John Henry Newman y Edith Stein, una en Italia y otra España. La italiana ha celebrado su primer congreso en 2017: "Maestri perché testimoni. Pensare il futuro con John Henry Newman e Edith Stein", Convegno Internationale, Iusve, Venezia-Mestre, 19-20 gennaio 2017, Istituto Universitario Salesiano Venezia. Las actas del congreso están publicadas en la obra colectiva del mismo título por LAS-Roma Lateran University Press, 2017.

La asociación española, recientemente creada, no ha celebrado por el 
momento eventos públicos, y su presencia en la escena académica se debe a la página WEB de la Asociación de Amigos de J. H. Newman y E. Stein (ANYS ${ }^{8}$. Esta asociación recoge en su Web las actas del congreso italiano y da cuenta de numerosas actividades, asociaciones y fundaciones dedicadas al estudio de cada uno de los dos pensadores.

La convergencia de ambos autores se da en el peculiar personalismo de ambos, entendido como primado de la autoconciencia personal, y como soberanía de la libertad personal. También hay convergencia en otros puntos: los dos tienen una concepción de la relación entre individuo y comunidad basada en la libertad, los dos son conversos, ninguno de los dos tiene sus raíces existenciales y culturales en los ámbitos de la Iglesia católica, ninguno de los tiene una posición afín a la de la jerarquía oficial en lo que al liberalismo se refiere, y ninguno de los dos adoptan actitudes cismáticas, sino de cooperación con la autoridad y acatamiento de ella.

Esta concepción del primado de la conciencia y de la persona tiene una larga historia en la cultura occidental, de la cual Newman y Edith Stein son quizá los últimos eslabones.

Ellos dos representan las posiciones del cristianismo de los derechos humanos, las de las iglesias cristianas más liberales, entre las que se cuentan las iglesias anglicanas, las luteranas y la iglesia católica alemana. En oposición a ellas se sitúan las posiciones del cristianismo del Antiguo Régimen, entre las que se pueden contar la iglesia católica polaca, la irlandesa y la española, entre otras.

\section{La persona y la conciencia en los inicios de la modernidad. John Locke}

En la historia del cristianismo europeo, es decir, en la historia de la Cristianad, el primado de la conciencia lo proclama por primera vez con valor oficial Urbano II (papa entre 1088 a 1099). Lo fundamentan teológicamente en textos del Nuevo Testamento Pedro Lombardo, el maestro de las sentencias (1096-1160), y Tomás de Aquino (1225-1274). La cuestión se 
reelabora durante la Edad Moderna9, en el siglo XX se proclama de nuevo en el Concilio Vaticano II (1963-1965), y después, lógicamente, en las canonizaciones de Stein en 1998 y de Newman en 2019.

El punto de partida del personalismo de Newman se encuentra en la concepción de la persona y la conciencia de John Locke. En el capítulo XXVII del libro II del Ensayo sobre el entendimiento humano, Locke sostiene que el hombre es su autoconciencia, hasta el punto de que, si el alcalde de mi ciudad tiene la misma autoconciencia que yo, entonces es la misma persona que yo $^{10}$.

Locke conoce bien la elaboración ontológica de la noción de persona a partir de la formación del dogma cristológico de Nicea. Apoya a Newton en sus reticencias ante la fórmula dogmática de Nicea y le defiende de las acusaciones de arrianismo que se le hacen ${ }^{11}$.

Por otra parte, en el Segundo tratado sobre el gobierno civil, desarrolla una ontología de la persona y de la libertad, en relación con la constitución contractual de la sociedad y con la democracia. En el medievo se pueden encontrar unos amplios antecedentes de la libertad moderna ${ }^{12}$, pero los desarrollos de Locke constituyen una fundamentación inmediata de los modernos sistemas políticos democráticos.

El modo en que Locke aplica su concepción de la persona y de la libertad a la vida práctica se encuentra en la Carta sobre la tolerancia ${ }^{13} \mathrm{y}$ en el Segundo tratado sobre el gobierno civil ${ }^{14}$.

9 Cfr., Choza, J., Religión oficial y religión personal en la época histórica, Sevilla: Thémata, 2020.

10 Locke, Ensayos sobre el entendimiento humano, México: FCE, 1956. Benito Vicente, José Oscar, "El problema de la identidad personal en la filosofía analítica". Daimon. Revista de Filosofía, N. 28, 2003.

11 Pfizenmaier, Thomas C., "Was Isaac Newton an Arian?", Journal of the History of Ideas, Volume 58, Number 1, January 1997, pp. 57-80. Sobre la historia de elaboración de la ontología de la noción de persona, Cfr., Choza, J., Antropología filosófica. Las representaciones del sí mismo, Sevilla: Thémata (2) 2020, cap. 3.

12 Garay, J., El nacimiento de la libertad. Precedentes de la libertad moderna. Sevilla: Themata, (2) 2017.

13 Locke, John, Mellizo, Carlos, ed. Ensayo y carta sobre la tolerancia ( $2^{\mathrm{a}}$ edición). Madrid: Alianza Editorial, 2014.

14 Locke, John, Segundo tratado sobre el gobierno civil, Mellizo, Carlos, ed., Madrid: Tecnos, 2010. 
Basa su doctrina sobre la tolerancia en el hecho de que, en la práctica, no se puede saber el modo en que cada persona en concreto concibe a la divinidad, y en que, por eso mismo, tampoco se puede imperar una determinada concepción. Ni la actividad subjetiva de creer ni el contenido de lo que se cree, dependen de la voluntad del individuo.

Por lo que se refiere a la constitución de la sociedad y la legitimidad del estado, el fundamento de ambos está siempre en el contrato social, en la voluntad libre de los ciudadanos de afirmar a ambos, y en el compromiso, contraído mediante juramento ante Dios, de apoyar a ambos ${ }^{15}$.

Por eso, y a pesar de los principios sobre la tolerancia, los ateos y los católicos no pueden ser ciudadanos de una sociedad y un estado democrático moderno. Los ateos porque no pueden comprometerse ante ningún Dios. Los católicos, porque ya tienen vinculada su conciencia a una autoridad humana externa a la sociedad democrática, aunque sea el Vicario de Cristo, el papa, y no pueden actuar según la soberanía de su conciencia de modo inmediato, para fundar esa sociedad democrática. Locke entiende que no se puede ser a la vez católico e inglés, como no se podía ser no-católico y español, desde 1492 a $1978^{16}$.

Estos principios de la ontología y la ética de la autoconciencia, que Locke aplica a la sociedad civil y al Estado, son los que Newman aplica a la relación del fiel cristiano con la fe cristiana y con la Iglesia, y más tarde Edith Stein, aunque sin relación con Locke, aplica a las relaciones entre el individuo y la comunidad.

\section{La persona y la conciencia tras la caída del Antiguo Régimen. Newman y el liberalismo}

Newman nace en 1801 y se mantiene anglicano hasta su conversión en 1845,

15 Segundo tratado sobre el gobierno civil, capítulo 8, "Del origen de las sociedades políticas".

16 Es decir, sin estar bautizado, un español no podía, entre otras cosas, contraer matrimonio hasta 1978, pues hasta entonces no hay matrimonio civil en España, sino solamente matrimonio sacramental. Cfr., Arechederra, Luis, Matrimonio civil y libertad religiosa en España (crónica jurídica), Madrid: Dykinson, 2020. 
que acontece, pues, "In mezzo del camin de la mia vita", como declara Dante en el comienzo de la Divina Comedia.

Las motivaciones inmediatas de su conversión surgen de sus reflexiones sobre el desarrollo histórico del cristianismo, y de su convicción de que una religión es verdadera si está viva, si se desarrolla y se actualiza, al ritmo de los procesos de maduración de sus fieles, como expone en su Ensayo sobre el desarrollo de la doctrina cristiana ${ }^{17}$. Encuentra que esa vitalidad y esa maduración se da en la iglesia católica, pero no en la anglicana.

Pero según sus hábitos existenciales, culturales e intelectuales, no puede convertirse, no puede pasar a formar parte de la Iglesia católica, no puede pasar a apoyar mediante juramento la sociedad de todos los católicos y la jerarquía que los gobiernan, si no es comprometiéndose personalmente según la soberanía de su autoconciencia.

Newman salva la contradicción entre la sinceridad de su entrega y su juramento, por una parte, y la sujeción al vicario de Cristo, el papa, por otra, por el procedimiento de declarar, como hace, que "El primer vivario de Cristo es la conciencia". Su apoyo y su sujeción a la Iglesia católica no dimanan en primer lugar de su vinculación al Vicario de Cristo, sino de la identidad entre su persona y su autoconciencia.

Esta proclamación y esta tesis no aparecen explícitamente como una condición previa a la conversión, pero, en el desarrollo histórico del cristianismo de la iglesia católica, esa tesis es la única suya que recoge literalmente el Catecismo de la Iglesia Católica de $1992^{18}$.

Trece años antes de su conversión, el 15 de agosto de 1832, el papa Gregorio XVI publica la encíclica Mirari vos, en la que condena el liberalismo en general, desautoriza y en algunos casos excomulga a alguno de los intelectuales católicos franceses liberales. Los agrupados en torno al diario L’Avenir, propugnan la desconfesionalización del estado, porque propugnan

17 Newman, J.H., Ensayo sobre el desarrollo de la doctrina cristiana, Salamanca: Centro de Estudios Orientales y Ecuménicos "Juan XXIII", 1997; Cfr., Garrido Luceño, J.M., Desarrollo doctrinal del cristianismo, Sevilla: Thémata, 2019.

18 Catecismo de la Iglesia Católica, N. 1776 "La conciencia es el primero de todos los vicarios de Cristo". La tesis de Newman de que la conciencia es el primer vicario de Cristo se encuentra en la Carta al Duque de Norfolk, de 1875, ed. española (incompleta), Madrid: Rialp, 2013. 
una sociedad cuya vida cristiana no se apoye en la imposición del poder político, sino en la autoconciencia libre de los ciudadanos.

Newman rechaza el estado confesional, porque ve el estado confesional anglicano como una rémora para el despliegue espiritual de la iglesia anglicana, y como una condena al anquilosamiento. Después de su conversión, sigue rechazando el estado confesional: sabe que la encíclica Mirari vos no ha sido transmitida a los fieles por los obispos ingleses, debido a que los liberales ingleses, que piden la desconfesionalizacion del estado anglicano y la libertad religiosa, son los aliados naturales de los católicos ingleses.

Newman rechaza la confesionalidad del estado del imperio británico y de la iglesia anglicana, en los que él ve un posicionamiento arriano. En el estado y en la iglesia anglicanos ve una especie de auto-deificación, una afirmación desconsiderada del valor divino de lo humano, de lo institucional estatal, por encima de lo espiritual genuinamente religioso ${ }^{19}$.

Pero, por otra parte, también rechaza el protestantismo liberal en la medida que asume un subjetivismo arbitrario. El cristianismo tiene una historia y unas creencias con un contenido objetivo, que, aunque han sido transmitidas en versiones continuamente actualizadas y renovadas, por tratarse de una doctrina viva, mantiene una identidad constante y reconocible.

Ante tantas acusaciones que se le hacen de antipatriota y de protestante liberal, Newman se sitúa en el término medio, como declara en la Apologia por vita sua. Se sitúa junto a los liberales franceses, especialmente Montalambert, con quien se siente más en sintonía, y comparte su lema de "una iglesia libre en un estado libre"20.

Newman entiende que la ortodoxia es un término medio entre dos extremos, entre el anquilosamiento en una tradición que se va agostando y va agostando a los fieles, y el vanguardismo actualista que vacía la religión de contenido, para dar al espíritu una libertad que no implica lealtad y fi-

19 Williams, Rowan, Arrio. Herejía y tradición. Salamanca: Sígueme, 2010. Desde este punto de vista, no sólo el estado victoriano, sino en general el estado socialista, desde sus formulaciones de Feuerbach y Marx hasta el estado de bienestar contemporáneo, puede verse como una o múltiples formas de arrianismo.

20 Newman, John Henry, Apologia por vita sua, ed. Ian Ker, London: Penguin, 1994, note A, Liberalism, pp. 252-262. 
delidad a una tradición, una libertad que cancela su identidad, como ocurre con el protestantismo liberal ${ }^{21}$.

Newman no puede encontrar ningún tipo de apoyo, y ni siquiera comprensión, en Roma. El papa con el que más tiempo coincide es Pio IX, que gobierna la Iglesia Católica desde 1845 a 1878, y es uno de los mayores oponentes a la desconfesionalización del estado, al estado democrático, y al liberalismo en general.

Los papas no solo no quieren ningún entendimiento con los liberales franceses ni, en general, continentales, sino, sobre todo, lo que le piden y exigen de él, como declara con amargura en la Apologia, son conversiones de más obispos anglicanos, para reforzar el prestigio y el poder de la Iglesia católica en la Cristiandad en crisis. Roma está preocupada, sobre todo, por el influjo temporal y su ascendencia sobre Europa, declara con la misma percepción que a la vez que él tiene Dostoievski en el otro extremo del continente.

Newman apela al sensus fidei fidelium, al sentido de la fe de los fieles, para legitimar su pensamiento y para asegurarse a sí mismo de su posición, y se refugia en el oratorio, donde muere después de una vida de una honestidad insobornable ${ }^{22}$.

Newman sabe que en el sentido de la fe de todos los fieles, y no sólo el de la jerarquía, en el sensus fidei fidelium, es donde únicamente radica la infalibilidad, en lo que se ha vivido en todas partes, siempre y por todas las personas ("quod ubique, quod semper, quod ab omnibus creditum est") 23.

Es una apelación a la fe de todos los cristianos, también de los laicos, del pueblo fiel, que a lo largo del segundo milenio ha estado cada vez más marginado a beneficio de un cierto corporativismo de la jerarquía, a beneficio del clericalismo.

Esa apelación de Newman da lugar a los movimientos del laicado en

21 Henderson, John B., The construction of orthodoxy and heresy. Neo-Confucian, Islamic, Jewish and Early Christian Patterns, New York; SUNY, 1998, cap 3.

22 Cfr., Comisión Teológica Internacional, El "sensus fidei" en la vida de la Iglesia, Madrid: BAC, 2014. Sobre los fieles laicos como factores del "sensus fidei", Cfr. Botero Giraldo, J. Silvio, "Protagonismo de pareja. Un ministerio a ejercitar", Carthaginensia, XVI, 2000, N. 30.

23 "El Canon de Vicente de Lerins: "Id teneamus quod ubique, quod semper, quod ab omnibus creditum est", J. Madoz, Gregorianum, Vol. 13, No. 1 (1932), pp. 32-74. 
el Concilio Vaticano II, que encuentra una de sus expresiones en los movimientos sinodales. Después del Concilio, los Sínodos rivalizan con los Concilios en cuanto que en estos los "padres conciliares" son sobre todo clérigos, mientras que en el Sínodo, las decisiones recaen también sobre toda la comunidad, pero de ella forman parte, y con cierto peso, los laicos ${ }^{24}$.

La fundación de la iglesia como sociedad, su contenido vivo, y lo que garantiza su ortodoxia, es la vitalidad de sus fieles, que se muestra en la continua actualización y renovación de sí misma, desde su libertad y su identidad, como ocurre con las sociedades democráticas que Locke diseña y describe. Hay analogía entre el modelo de la sociedad contractual democrática moderna, y la sociedad eclesial basada en el sensus fidei fidelium, el sentido de la fe de los fieles, que tiene su expresión en los sínodos.

Por otra parte, Newman se refugia, lejos de las grandes órdenes e instituciones católicas con demasiado poder y demasiada responsabilidad, en el oratorio de San Felipe Neri, una institución de carácter autónomo en cada localidad, que él funda en Oxford cuando se convierte al catolicismo, para evitar la soledad en la que él ve que viven una gran cantidad de sacerdotes católicos.

\section{$5 \cdot$ La persona y la conciencia en el pensamiento del siglo XX. Edith Stein y la autenticidad}

Si la vida de Newman se distingue por una honestidad y una búsqueda insobornable de la verdad, la de Edith Stein, es quizá la que, en el siglo XX, más destaca por la pretensión de autenticidad y de realización personal, también a partir de la libertad de la autoconciencia soberana.

Es de profesión filósofa, profesora, y no tiene ningún cargo público ni en la universidad ni en la Iglesia. Es judía y mujer. Es de carácter introvertido, muy volcada hacia su interior. Y además se forma en el seno de una

24 Reyes Vizcaíno, Pedro María, Organización y desarrollo del Sínodo de los Obispos, en Organización de la Iglesia Universal, https://www.iuscanonicum.org/index.php/organizacion-eclesiastica/organizacion-de-la-iglesia-universal/175-organizacion-y-desarrollo-del-sinodo-de-los-obispos. 
corriente filosófica especialmente equipada para el análisis de la interioridad, la libertad y la identidad, la escuela fenomenológica fundada por Edmund Husserl.

En esa escuela, y a la vez que ella, se inicia igualmente otro filósofo que dedica también la mayor atención al análisis de la interioridad, la libertad y la identidad, Martin Heidegger, y después de que ella se ha marchado, se incorpora otro filósofo judío que, posteriormente, muestra mucha afinidad con su pensamiento, Enmanuel Lévinas.

\subsection{El sí mismo y la autenticidad}

Como dice Locke, ni la certeza de la fe ni el contenido de lo que se cree (la fides qua y la fides quae, como dice la teología) son controlables por la voluntad. La fe no resulta de una elección voluntaria, pero la adhesión a una comunidad como la sociedad civil o la iglesia, sí que brota de la elección voluntaria y del fondo más radical del sí mismo personal.

Precisamente porque los católicos no disponen de sí mismos según la elección de su conciencia, es por lo que Locke piensa que no pueden fundar una sociedad democrática.

¿Qué es lo que le pasa a la persona cuando cree, cuando se fía, cuando se compromete y cuando jura? Lo que le pasa es que se pone en juego una conexión entre lo que, desde San Agustín a Descartes y a Freud, los filósofos han llamado el sí mismo y el yo, la persona se sitúa en esa conexión, se encuentra consigo misma, y realiza los actos más genuinamente personales de los que el ser humano es capaz. El acto más genuinamente personal que puede alcanzar.

Como muchos otros filósofos, Edith Stein cree que el hombre vive ordinariamente en su conciencia, en su atención, en su yo, y que normalmente está lejos de sí mismo. San Agustín describe el fondo del sí mismo como el lugar desde el que Dios convoca al hombre, y como el lugar que queda sepultado y oculto por la triple concupiscencia, efecto del pecado original, por la concupiscencia de la carne, la concupiscencia de los ojos y la soberbia de la vida ${ }^{25}$.

Después de San Agustín, quienes mejor describen esa situación, y en unos términos más modernos, más comprensibles para nosotros, son 
Rousseau y Kant.

En el Discurso sobre las ciencias y las artes, Rousseau explica que, los que viven preocupados solamente del triunfo social, son esos que solicitan siempre de los demás lo que no son capaces de buscar y encontrar en y por sí mismos, y por eso no tienen más que "un exterior engañoso y frívolo: honor sin virtud, razón sin sabiduría y placer sin dicha" ${ }^{26}$. Lo mismo dice Kant cuando describe las tres pasiones de la vida social, tener, poder y valer. La preocupación por el éxito social, y su logro, le hace olvidarse con facilidad de ser sí mismo, de ser honesto ${ }^{27}$.

Husserl, y las escuelas fenomenológicas detectan y analizan esa escisión entre el sí mismo y el yo, ese alejamiento y extrañamiento mutuo, que describen como un tipo de alienación. Los análisis de Edith Stein y Heidegger son especialmente pertinentes en este contexto.

Heidegger le llama "la caída en el se impersonal", en el hacer lo que se hace, decir lo que se dice, y vivir como se vive, al margen del sí mismo personal. Y dedica buena parte de su obra más emblemática, El ser y el tiempo, a describir las formas de ser sí mismo de un modo impropio y las de ser sí mismo de un modo propio, a describir los modos de ser inauténtico y de ser auténtico ${ }^{28}$.

Ser auténtico, o lo que es lo mismo, actuar de un modo personal y libre, es la articulación congruente y adecuada del sí mismo y el yo, la acogida plena del sí mismo en el yo y del yo en el sí mismo.

\subsection{Realización personal y unión mística}

La tarea filosófica de Edith Stein consiste, sobre todo, en analizar cómo es la experiencia que tiene cada hombre de la persona, en averiguar de qué es de lo que tiene experiencia cuando tiene experiencia del sí mismo propio y del sí mismo de los demás ${ }^{29}$.

26 Rousseau, J.J., Discurso sobre las ciencias y las artes, en Del contrato social. Discursos, Madrid: Alianza, 1985, p. 286.

27 Kant, E., Antropología en sentido pragmático, Madrid: Alianza, 1991.

28 Cfr., Ferrer, U., y Sanchez-Migallón, S., La ética de Edmund Husserl, Sevilla: Thémata, (2), 2018; Heidegger, M., El ser y el tiempo, México: FCE, 1993, §§ 35-38 y 54-60.

29 Cfr., Gutiérrez Aguilar, Ananí, La experiencia de la persona en el pensamiento de Edith Stein, Sevilla: Thémata, 2018. 
Dedica su libro La estructura de la persona, a completar, a partir de la obra de Tomás de Aquino y de Husserl, una psicología filosófica fenomenológica, para poner en claro que es el yo, el sí mismo, el intelecto, los sentimientos, la voluntad, la libertad, y qué experiencia tenemos de su funcionamiento ${ }^{30}$.

Dedica su libro Ser finito y ser eterno a perfilar, también a partir de la obra de Tomás de Aquino y de Husserl, una ontología fenomenológica de los vivientes intelectuales, para poner en claro qué es en ellos, lo sustancial y lo accidental, lo permanentemente en acto (acto primero) y lo operativo en diversos momentos (acto segundo), lo esencial y lo existencial, lo ontológicamente fundamentante y lo fundamentado ${ }^{31}$.

Finalmente, poco antes de ser apresada en el Carmelo de Echt, en Holanda y llevada a Auschwitz en 1942, termina de escribir La ciencia de la cruz, donde pone en claro la relación entre autoconciencia, voluntad, libertad y sí mismo32.

$\mathrm{Su}$ tesis es que cuando un hombre quiere sobre todo ser honesto y lo es (ella no emplea el término "ser auténtico", sino "ser honesto"), lo que quiere es ser sí mismo, y lo es, y lo que alcanza es su grado máximo de libertad. La persona se posee plenamente a sí misma, el yo posee al sí mismo y el sí mismo acoge plenamente al yo. La persona llega a la sustancia del alma, se encuentra con su fundamento, lo asume, lo acoge y lo posee, a la vez que es asumida, acogida y poseída por su fundamento, es decir, por Dios, independientemente de la confesión religiosa y de la adscripción religiosa institucional de la persona.

Stein entiende que la experiencia del sí mismo propio, o del sí mismo de otra persona, es experiencia, en el fondo, de Dios. Esto de algún modo está presente a lo largo de toda su obra, pero donde aparece perfilado de un modo máximamente claro y distinto es en el epígrafe "Alma, yo y libertad" de La ciencia de la cruz, tras los análisis fenomenológicos de los comentarios de Juan de la Cruz a los poemas, La noche oscura, Subida al monte Carmelo, Cántico espiritual, Llama de amor viva, contrastados con el texto de Las mo-

30 Stein, Edith, La estructura de la persona humana, Madrid: BAC, 1998.

31 Stein, Edith, Ser finito y ser eterno, México: FCE, 1997.

32 Stein, Edith, La ciencia de la cruz, Burgos: Monte Carmelo, 2006, apartado "Alma, yo y libertad", pp. 212-221. 
radas de Teresa de Jesús.

Edith Stein se apoya, para realizar sus análisis sobre el sí mismo como fundamento, en Tomás de Aquino y en sus enfoques aristotélicos, especialmente en la tesis de que, en el caso del ser humano, la actividad intelectiva es "crecimiento hacia sí mismo y el acto" (De anima, II, 5, 417b 6-7), en la tesis de que el último referente de la actividad del espíritu humano, especialmente la de su desarrollo en tanto que espíritu, es Dios mismo.

La tesis de que la experiencia del sí mismo de otra persona es la experiencia de Dios, aparece también como el motivo fundamental de la obra de Enmanuel Lévinas (1906-1996), que se expone de modo paradigmático en De otro modo que ser o más allá de la esencia, publicado en $1974^{33}$.

Lévinas llega a la escuela fenomenológica de Friburgo y trabaja con Husserl y Heidegger en los años 1927 y 1928, cuando Stein ya se ha marchado. Durante la guerra pasa años en un campo de prisioneros, y a partir de los años 70 empieza a difundirse su obra. Es posible que no haya habido conexión entre el pensamiento de ambos.

Hay una afinidad, que es el tema de la intersubjetividad, muy propia del pensamiento judío, pero la filosofía de la intersubjetividad de Lévinas se desarrolla en la línea de una ética de la trascendencia absoluta en relación con el Otro sagrado, misterioso y anónimo, y la de Stein se despliega en la línea de una ontología de la presencia de Dios, amorosa, personal y personalizante.

El pensamiento de Lévinas está en sintonía con la mística germana, que es una mística del abismo y de la ausencia, y el de Stein con la mística española, que es una mística del amor y de la presencia.

Por otra parte, la experiencia de la persona de Edith Stein, es también una experiencia de la comunidad y de la libertad política. Aunque Edith Stein está dentro de los cuadros institucionales de la iglesia católica, su descripción de la experiencia de la persona como experiencia de Dios, idéntica a la experiencia mística de Juan de la Cruz y Teresa de Jesús, es para ella una experiencia que pertenece al común de los hombres, como la experiencia del otro de Lévinas.

Según Edith Stein, desde el punto de vista ontológico y desde el pun-

33 Lévinas, Emmanuel, De otro modo que ser o más allá de la esencia. Salamanca: Ediciones Sígueme, 1995. 
to de vista psicológico, no hay diferencia entre la unión mística y el ser propiamente sí mismo, o sea, la honestidad, eso que Heidegger llama autenticidad, y que se toma como definición de la secularización, como relación con el sí mismo ${ }^{34}$. En esa honestidad, que obviamente no tiene como requisito la adscripción a iglesias ni a institución religiosa alguna, la persona se posee a sí misma y posee a Dios, de la misma manera que Dios se posee a sí mismo y posee a la persona ${ }^{35}$.

Esto es muchos más de lo que Locke y Newman se habrían atrevido a decir, y Stein lo afirma de modo sencillo, pacífico y rotundo. Como si percibiera una especie de comunión de los santos, de comunión de la iglesia triunfante, en la unidad de todos los hombres de buena voluntad integrados en el género humano. En realidad, en términos aristotélico-tomistas, si desde el punto de vista ontológico el desarrollo del espíritu es "crecimiento hacia sí mismo y el acto", no tiene mucho sentido circunscribir las posibilidades reales de ese crecimiento, en exclusiva, a unos procesos burocráticos y administrativos gestionados por una institución empírica, histórica, particular

Como Newman en el Oratorio, Edith Stein encuentra su refugio también en el Carmelo, en la orden carmelita. Como él, no tiene más hogar que la cruz, y, a diferencia de él, muere mártir en el campo de exterminio polaco, dando testimonio de su fe en la humanidad y de su amor a ella.

\section{$6 \cdot$ Newman y Stein, guías de las iglesias cristianas del siglo XXI}

La proclamación de la autoconciencia como primer vicario de Cristo, de la autenticidad como forma máxima de profesión de fe y de unión con Dios, y de la vinculación mediante ambas de la persona individual a las demás personas y a la comunidad, sitúan a Newman y Stein como referentes y pioneros en el desarrollo de las iglesias cristianas en el siglo XXI. Al menos, y sobre todo, para la iglesia católica, después de la canonización de Edith

34 Cfr., Roldán Gómez, Isabel, Aunque dios no existiera. La crisis de la secularización, THÉMATA. Revista de Filosofía, № 53, enero-junio (2016) pp.: 311-326.

35 Cfr., Gutiérrez Aguilar, Ananí, La experiencia de la persona en el pensamiento de Edith Stein, Sevilla: Thémata, 2018, cap. IV. 
Stein por Juan Pablo II en 1998, y de la canonización de Newman por Francisco en 2019.

En una cierta sintonía con la Carta sobre la tolerancia de Locke, después de la actualización de su autoconciencia y de su situación en el mundo realizada a partir del Concilio Vaticano II, la iglesia católica lleva a cabo una especie de privatización del dogma y de la moral, como un modo de reconocer a la autonomía de la conciencia la prioridad que le corresponde ${ }^{36}$.

El proceso de privatización del dogma pasa inadvertido porque, sin proclamaciones públicas, cesa la práctica de quemar herejes, después cesa la práctica de excomulgar a los fieles por su interpretación de los dogmas, $\mathrm{y}$ a finales del siglo XX deja de importunarse a nadie por sus formulaciones teológicas. A lo sumo se le retira la autorización para enseñar en las universidades de la Iglesia, o se le margina discretamente, pero nada más.

A diferencia de la privatización del dogma, para la cual es difícil señalar un momento y una acción por la que se lleve a cabo, la privatización de la moral la realiza el Papa Francisco mediante la publicación de unos documentos que provocan escándalo y conmoción en la conciencia de los sectores más conservadores. Esos documentos son los siguientes

1. Las dos Cartas "motu proprio date" "Mitis Iudex Dominus Iesus" e "Mitis et misericors Iesus" sobre la reforma del proceso canónico para las causas de declaración de nulidad de matrimonio, respectivamente en el Código de Derecho Canónico y en el Código de los Cánones de las Iglesias Orientales, de 8 de septiembre de 2015.

2. La Bula "Misericordiae Vultus", El rostro de la misericordia, de convocación del jubileo extraordinario de la misericordia, de 11 de abril de 2015. Con ocasión de ella, se concede un permiso temporal para que los sacerdotes puedan absolver del pecado de aborto a quienes lo han practicado y que estén arrepentidos de corazón durante el Jubileo de la Misericordia o Año Santo, entre el 8 de diciembre de 2015 y el 20 de noviembre de 2016.

3. La exhortación apostólica "Amoris laetitia", La alegría del amor, sobre el amor en la familia, de 19 de marzo de 2016, después de los dos

36 Cfr., Choza, J., Religión oficial y religión personal en la época histórica, Sevilla: Thémata, 2020, caps. 4 y 5. 
sínodos sobre la familia celebrados en 2015 y 2016.

Mediante estos documentos se agiliza la práctica de la nulidad de los matrimonios canónicos para aproximarlos a la de la disolución de los matrimonios civiles, por una parte, y por otra se facilita levantar la pena canónica de excomunión a las personas que practican el aborto, es decir, se cancela su estatuto de pecadores públicos.

La alegría del amor, además, hace valer en el ámbito del derecho público de la Iglesia el principio canónico y teológico del primado de la conciencia soberana, razón por la cual se establece que no se debe negar el sacramento a ninguna persona que se acerque a él, aunque se conozca su condición de divorciado, de homosexual, etc., porque la relación del sacramento con la conciencia del interesado tiene primacía sobre la norma canónica general.

Estos documentos provocan escándalo en las conciencias que toman como señas de identidad cristiana las señas culturales de la condena canónica del aborto, del divorcio y de la homosexualidad, pero no en las que toman como señas evangélicas de identidad cristiana el amor y la misericordia ("En esto conocerán todos que sois mis discípulos, si tuviereis amor los unos con los otros" Juan 13:35).

Las iglesias que a partir del siglo XXI han abierto institucionalmente el máximo ámbito de libertad a sus fieles, las que les han reconocido la plenitud de los derechos humanos como derechos fundamentales, son las iglesias anglicanas y luteranas. Son iglesias nacionales que, insertas en los marcos de las constituciones políticas de los diversos países en que se incardinan, han sido impulsadas a ello por el orden democrático de sus comunidades políticas, $\mathrm{y}$, a la vez, por el sensus fidei fidelium de sus fieles.

Las iglesias católicas de España, Polonia e Irlanda, se encuentran en un caso distinto. La iglesia católica española podría acoger plenamente los derechos humanos como derechos fundamentales, según la constitución política democrática vigente en el país. Pero de hecho no puede hacerlo, aunque los católicos españoles quisieran, aunque contara con el sensus fidei fidelium de los laicos españoles, porque la iglesia católica española no tiene carácter autónomo nacional, está integrada en la Iglesia Católica Universal, y tienen una jerarquía autoritaria que no sintoniza con su laicado.

Las iglesias católicas de Polonia e Irlanda, se ubican en países en los 
que no hay un reconocimiento pleno de los derechos humanos en los derechos fundamentales de sus constituciones políticas, al menos en lo que a discriminación por razón de sexo se refiere. Esa situación tiene su reflejo también en una cierta división en el sensus fidei fidelium de los fieles católicos polacos y los irlandeses, especialmente entre los laicos y la jerarquía. Estos fieles se dividen entre los que desean la superación de las discriminaciones en el Estado y en la Iglesia Católica, generalmente los laicos, y los que desean mantenerlas, generalmente la jerarquía.

En Alemania es donde aparece con mayor claridad una escisión entre la ortodoxia católica romana, por una parte, y, por otra el sensus fidei fideliun de los fieles laicos en sintonía con los obispos católicos alemanes. En la segunda década del siglo XXI, los obispos alemanes, de un modo cada vez más unánime, han solicitado de Roma la eliminación de cualquier discriminación por razón de sexo, para el desempeño de cualquier función o actividad eclesiástica, como lo han hecho las iglesias anglicanas y luteranas.

La negativa de Roma, lleva al borde del cisma a la iglesia católica alemana en 2019, precisamente mientras se canoniza a Newman, y genera una tensión entre la conferencia episcopal alemana y el vaticano que se mantiene con las mismas características en 2020.

En Rumanía, un conflicto entre los laicos y la jerarquía se ha resulto a favor de los ciudadanos libres y de los laicos, en el referéndum para modificar la constitución, celebrado el 7 de octubre de 201837.

El referéndum se plantea cuando un americano y un rumano homosexuales, que contraen matrimonio en Bélgica, se instalan a vivir en Rumanía, solicitan los beneficios que la constitución concede a las familias, y al serles denegados recurren al tribunal europeo.

El tribunal europeo obliga al tribunal supremo de Rumanía a atender la petición, de acuerdo con la constitución rumana. Para evitar ceder a la petición de los actores y del tribunal europeo, el Estado rumano, de acuerdo con las dos iglesias cristianas autocéfalas del país, la ortodoxa rusa y la ortodoxa rumana, que integran el $98 \%$ de la población, convocan un referéndum para modificar la constitución:

El referéndum propone cambiar la redacción del artículo 48.1 de la

37 Cfr., Choza, J., El sexo de los ángeles. Sexo y género desde las bacterias a los robots, Sevilla: Thémata, 2020, § 72.1.- Familias LGTB. La constitución de Rumanía. 
Constitución rumana para sustituir en la definición del matrimonio la expresión "entre los esposos" por la expresión "entre un hombre y una mujer", que excluye que los esposos puedan ser del mismo sexo (https://www. dosmanzanas.com/2018/10/).

El Tribunal Constitucional da el visto bueno a la consulta sobre la reforma aprobada por el Parlamento unos días antes. Los resultados del referéndum son válidos si participa al menos el $30 \%$ del censo electoral y los votos a favor superan el $50 \%$.

El domingo 7 de octubre de 2018 se celebra el referéndum, que no alcanza el mínimo del 30\% de participación del censo electoral, requerido para la aprobación del asunto propuesto.

Con este resultado se declara que la expresión "entre los esposos" se entiende en el sentido de "entre dos personas en general independientemente del sexo", y que la Unión Europea acepta el reconocimiento legal de una variedad indefinida de formas matrimoniales, incluidos los 22 tipos de matrimonio del mismo sexo que registran los antropólogos en África ${ }^{38}$. Asimismo, se declara el reconocimiento legal de una variedad indefinida de agrupaciones domésticas, con su prole incluida.

No consta que en las campañas para el referéndum rumano se hiciera alusión a las doctrinas de Newman y Stein, bastante ajenos, en tanto que católicos, a esa cultura. Pero la apelación a ambos a la vez, por parte de los católicos, en este momento histórico de desarrollo del cristianismo, tiene el sentido de proyectar luz sobre una serie de problemas de la sociedad del siglo XXI. Entre esos problemas se encuentran la articulación entre individuo y comunidad, la ubicación de la mujer en el mundo laboral y en la sociedad en general, las políticas educativas, y también las políticas eclesiásticas y religiosas.

La afirmación de la soberanía de la autoconciencia que Newman y Stein formulan, es un modo de hacerse cargo de uno de los mayores problemas que aqueja a las iglesias cristianas en el momento presente. Significa una disposición para el reconocimiento de la soberanía de la libertad de todos y cada uno de los fieles individuales, laicos y clérigos, del sensus fidei fideliun, de las formas de actualización de la fe cristiana, y de respeto a las autoridades legítimas. Requisitos necesarios para el desarrollo del cristia-

38 https://en.wikipedia.org/wiki/Same-sex_marriage. 
nismo del que habla Newman y cuyo estudió le llevó a la iglesia católica.

\section{7- Bibliografía}

Arechederra, Luis. Matrimonio civil y libertad religiosa en España (crónica jurídica), Madrid: Dykinson, 2020.

Benito Vicente, José Oscar. "El problema de la identidad personal en la filosofía analítica". Daimon. Revista de Filosofía, N. 28, 2003.

Catecismo de la Iglesia Católica, Madrid: Rialp, 2013.

Choza, J. Antropología filosófica. Las representaciones del sí mismo, Sevilla: Thémata (2) 2020, cap. 3.

Choza, J. El sexo de los ángeles. Sexo y género desde las bacterias a los robots, Sevilla: Thémata, 2020.

Choza, J. Metamorfosis del cristianismo: ensayo sobre la relación entre religió y cultura, Sevilla: Thémata,(2) 2018.

Choza, J. Religión oficial y religión personal en la época histórica, Sevilla: Thémata, 2020.

Comisión Teológica Internacional, El "sensus fidei" en la vida de la Iglesia, Madrid: BAC, 2014. Botero Giraldo, J. Silvio. "Protagonismo de pareja. Un ministerio a ejercitar", Carthaginensia, XVI, 2000, n. 30.

Ferrer, U., y Sanchez-Migallón, S. La ética de Edmund Husserl, Sevilla: Thémata, (2), 2018.

Garay, J., El nacimiento de la libertad. Precedentes de la libertad moderna. Sevilla: Themata, (2) 2017.

Garrido Luceño, J.M. Desarrollo doctrinal del cristianismo, Sevilla: Thémata, 2019.

Gutiérrez Aguilar, Ananí. La experiencia de la persona en el pensamiento de Edith Stein, Sevilla: Thémata, 2018.

Heidegger, M. El ser y el tiempo, México: FCE, 1993, §§ 35-38 y 54-60.

Henderson, John B. The construction of orthodoxy and heresy. Neo-Confucian, Islamic, Jewish and Early Christian Patterns, New York; SUNY, 1998.

Kant, E. Antropología en sentido pragmático, Madrid: Alianza, 1991.

Lévinas, Emmanuel. De otro modo que ser o más allá de la esencia. Salamanca: Ediciones Sígueme, 1995.

Locke, John. Ensayos sobre el entendimiento humano, México: FCE, 1956. 
Locke, John. Mellizo, Carlos, ed. Ensayo y carta sobre la tolerancia ( $2^{\mathrm{a}}$ edición). Madrid: Alianza Editorial, 2014.

Locke, John. Segundo tratado sobre el gobierno civil, Mellizo, Carlos, ed., Madrid: Tecnos, 2010.

Madoz, J. Gregorianum, Vol. 13, No. 1 (1932), pp. 32-74.

Mauti, Ricardo Miguel. "La recepción de Newman en la teología del siglo XX", Revista de Teología, XLII, N 87, 2005 (pp.417-462)

Newman, John Henry. Ensayo sobre el desarrollo de la doctrina cristiana, Salamanca: Centro de Estudios Orientales y Ecuménicos "Juan XXIII", 1997.

Newman, John Henry. Apologia por vita sua, ed. Ian Ker, London: Penguin, 1994, note A, Liberalism.

Pfizenmaier, Thomas C. "Was Isaac Newton an Arian?", Journal of the History of Ideas, Volume 58, Number 1, January 1997, pp. 57-80.

Redondo, Gonzalo. La Iglesia en el mundo contemporáneo, vol I, Pamplona: Servicio de Publicaciones de la Universidad de Navarra, 1981.

Reyes Vizcaíno, Pedro María. Organización y desarrollo del Sínodo de los Obispos, en Organización de la Iglesia Universal, https://www.iuscanonicum.org/index.php/organizacion-eclesiastica/organizacion-de-la-iglesia-universal/175-organizacion-y-desarrollo-del-sinodo-de-los-obispos.

Roldán Gómez, Isabel. "Aunque dios no existiera. La crisis de la secularización", Thémata. Revista de Filosofía, n. 53, enero-junio (2016) pp.: 311-326.

Rousseau, J.J., Discurso sobre las ciencias y las artes, en Del contrato social. Discursos, Madrid: Alianza, 1985.

San Agustín. Confesiones, Madrid: BAC, 1979, libro X.

Stein, Edith. La ciencia de la cruz, Burgos: Monte Carmelo, 2006, apartado

"Alma, yo y libertad", pp. 212-221.

Stein, Edith. La estructura de la persona humana, Madrid: BAC, 1998.

Stein, Edith. Ser finito y ser eterno, México: FCE, 1997.

Williams, Rowan. Arrio. Herejía y tradición. Salamanca: Sígueme, 2010. 